JPE (Jurnal Pendidikan Edutama) Vol. 7 No. 1 Januari 2020

P-ISSN : 2339-2258 (Print) E-ISSN: 2548-821X (Online)

http://ejurnal.ikippgribojonegoro.ac.id/index.php/JPE

\title{
ANALISIS KETERAMPILAN SISWA MELALUI MODEL DEMONSTRASI PADA PEMBELAJARAN TEMATIK DI SEKOLAH DASAR
}

\author{
Siti Fatimah Soenaryo ${ }^{1}$, Erna Yayuk $^{2}$, Kuncahyono ${ }^{3}$, Arina Restian ${ }^{4}$ \\ 1,2,3,4 Pendidikan Guru Sekolah Dasar, Universitas Muhammadiyah Malang \\ sitifatimahsoenaryo@yahoo.co.id \\ ernayayuk17@umm.ac.id \\ kuncahyono@umm.ac.id \\ arina.poenya@gmail.com
}

\begin{abstract}
The purpose of this research was to describe the student's skills through demonstration models in thematic learning and to find out the constraints of applying demonstration models in thematic learning in elementary schools. This research used a qualitative approach with research subjects of fourth-grade students at SDN Tlogomas 2 Malang City. The results of the research showed that the application of the demonstration model involved students in various learning situations. The theme of the learning material in this case, is the theme 1: The Beautiful Diversity: be grateful for diversity. The demonstration model is carried out by following the syntax or stages as follows: planning, implementation, and evaluation. The planning stage is done by making lesson plans and learning media, the implementation phase is done by integrating into groups, and evaluation is carried out by conducting question and answer as a form of further reflection. The obstacles faced by teachers are the lack of facilities and infrastructure to support learning such as media reality.
\end{abstract}

Keywords: Skills, demonstration model, thematic learning

Abstrak: Tujuan penelitian ini yaitu untuk mendeskripsikan keterampilan siswa melalui model demonstrasi dalam pembelajaran tematik dan mengetahui kendala penerapan model demonstrasi dalam pembelaajran tematik di sekolah dasar. Penelitian ini menggunakan pendekatan kualitatif dengan subjek penelitian siswa kelas IV SDN Tlogomas 2 Kota Malang. Hasil penelitian menunjukkan bahwa penerapan model demonstrasi melibatkan siswa dalam berbagai situasi pembelajaran. Adapun tema materi pembelajaran dalam hal ini yaitu tema 1 Indahnya Keberagaman: Bersyukur atas keberagaman. Model demonstrasi dilakukan dengan mengikuti sintak atau tahapan sebagai berikut perencanaan, pelaksanaan, dan evaluasi. Tahap perencanaan dilakukan dengan membuat RPP dan media pembelajaran, tahap pelaksanaan dilakukan dengan mengintegrasikan ke dalam kelompok, dan evaluasi dilaksanakan dengan melakukan tanya jawab sebagai bentuk refleksi selanjutnya. Kendala yang dihadapi guru yaitu kurangnya sarana dan prasarana penunjang pembelajaran seperti media realita.

Kata Kunci : Keterampilan, model demonstrasi, pembelajaran tematik 


\section{PENDAHULUAN}

Pembelajaran tematik di sekolah dasar mengintegrasikan berbagai ranah kompetensi siswa. Salah satunya terkait keterampilan dalam pembelajaran tari yang dikemas dalam pembelajaran tematik terpadu. Kompetensi ranah keterampilan merupakan kemampuan dalam melakukan serangkaian kegiatan yang melibatkan anggota tubuh yang berkaitan dengan kegiatan fisik (motorik). Penguasaan kompetensi keterampilan dalam kurikulum 2013 menjadi point penting karena siswa dituntut tidak hanya pandai dalam kognitif tetapi juga dalam afektif dan psikomotorik. Sebagaimana pendapat Prastowo (2013:125) menyatakan pembelajaran tematik merupakan proses pembelajaran yang penuh makna dan berwawasan multikurikulum.

\begin{tabular}{lccr}
\multicolumn{2}{c}{ Kurikulum } & 2013 & sebagai \\
kurikulum model & terbaru & yang \\
dicanangkan & oleh & pemerintah & juga
\end{tabular}
menjadi sarana untuk memperkenalkan budaya. Lebih lanjut hal ini dapat kita lihat pada buku Tematik Terpadu tema 1 yang berjudul "Indahnya Kebersamaan". Dalam buku ini keragaman budaya Indonesia di tampilkan secara sampling saja dengan mengangkat budaya dan tradisi masyarakat minang secara dominan. Melihat begitu ragamnya budaya Indonesia, tentunya tidaklah cukup hanya dalam upaya sampling saja, perlu di lakukan upaya lebih dari itu. Sebab interaksi dan informasi yang semakin global menambah kurangnya daya tarik dan minat generasi muda terhadap budaya, tradisi dan kesenian lokal. Kurangnya daya tarik dan minat ini tentu saja sangat mempengaruhi perolehan hasil belajar siswa pada materi muatan Seni Budaya dan Prakarya (SBDP).

Sementara itu disisi lain siswa selaku peserta didik harus mendapatkan lebih banyak hal positif untuk bekal mengembangkan potensinya agar tumbuh berkembang menjadi manusia yang beriman dan bertaqwa kepada Tuhan Yang Maha Esa, berbudi pekerti, terampil, berdisiplin, beretos kerja, menjadi warga negara yang demokratis serta bertanggung jawab baik jasmani maupun rohani. Sebagaimana yang termuat dalam Undang-Undang Nomor 20 Tahun 2003 tentang Sistem Pendidikan Nasional. Hal ini senada dengan (Baharuddin \& Esa, 2007:13) yang menyatakan usaha untuk mencapai kepandaian atau ilmu merupakan usaha manusia untuk memenuhi kebutuhannya mendapatkan ilmu atau kepandaian yang belum dipunyai sebelumnya.

Peraturan Pemerintah No. 28 Tahun 1993 tentang pendidikan dasar menjelaskan bahwa guru selalu dianggap sebagai pihak yang bertanggung jawab dalam mencapai suatu keberhasilan pendidikan terutama dalam meningkatkan hasil belajar siswa dalam pembelajaran. Oleh karena itu guru di tuntut berinovasi dan berkreasi sesuai dengan kebutuhan peserta didik sehingga pembelajaran yang dilakukan mampu melahirkan peserta didik yang terampil dengan nilai tuntas sesuai dengan standard ketuntasan belajar minimal. Ditegaskan dalam Permendikbud No 57 tahun 2014 pembelajaran tematik terpadu merupakan pendekatan pembelajaran 
yang mengintegrasikan berbagai kompetensi dari berbagai mata pelajaran ke dalam berbagai tema.

Berdasarkan observasi peneliti selama mengajar tematik di kelas IV-B SDN Tlogomas 2 Malang, ditemukan permasalahan pada siswa dalam hal kurangnya daya tarik dan minat untuk mempelajari tarian tradisional khas ranah minang yaitu "Tarian Bungong Jeumpa". Hal ini disebabkan beberapa meliputi 1) siswa merasa asing dan belom mengenal tarian tersebut, 2) Siswa merasa gerakan dan formasinya lebih sulit dibandingkan dengan tarian modern yang berkembang di masyarakat, 3) Siswa lebih sering menyaksikan kesenian lokal lain seperti dangdut, jaran kepang dan barongan di lingkungan tempat tinggal sekitar.

Berdasarkan permasalahan yang sudah dipaparkan untuk membangkitkan daya tarik belajar siswa terkait tarian daerah, serta meningkatkan pengetahuan dan nilai mereka pada muatan materi SBDP KD 3.3 maka seorang pendidik harus mempunyai berbagai model atau cara mengajar yang sesuai dengan apa yang menjadi kebutuhan dari para siswa tersebut. Salah satu alternatif dalam mengatasi permasalahan tersebut yaitu dengan menerapkan model pembelajaran. Model pembelajaran yang dapat diterapkan dalam pembelajaran yaitu model demontrasi. Model demontrasi merupakan model pembelajaran yang bertujuan untuk mengaktifkan siswa (student centered). Melalui model demonstrasi siswa dapat melakukan pembelajaran secara langsung berdasarkan instruksi dari guru. Berdasarkan penjelasan di atas maka peneliti tertatik untuk menganalisis penerapan model pembelajaran demonstrasi dalam pembelajaran tematik di kelas IVB SDN Tlogomas 2 Kota Malang.

\section{METODE PENELITIAN}

Pendekatan penelitian yang digunakan pada penelitian ini adalah kualitatif dengan jenis penelitian deskriptif. penelitian ini bersifat mengidentifikasi kompetensi keterampilan siswa melalui model demonstrasi. Lokasi yang digunakan adalah SDN Tlogomas 2 Kota Malang. Waktu yang digunakan dalam penelitian ini yaitu pada bulan Agustus 2018. Adapun subjek penelitian ini yaitu siswa kelas IV SDN Tlogomas 2 Kota Malang yang berjumlah 30 siswa. Teknik pengumpulan data yang akan digunakan dalam penelitian ini adalah angket, wawancara dan dokumentasi. Angket yang dibagikan dalam bentuk pertanyaan merupakan angket semi tertutup, dimana dalam angket tersebut sudah disediakan jawaban sehingga responden tinggal memilih jawabannya. Jawaban setiap item pada angket memiliki bobot skor sangat setuju $=5$; setuju $=4$; ragu-ragu $=3$; tidak setuju $=$ 2 ; sangat tidak setuju $=1$. Sedangkan teknik wawancara yang digunakan dalam penelitian ini adalah wawancara tidak terstruktur. Wawancara tidak terstruktur adalah wawancara bebas dimana peneliti tidak menggunakan pedoman wawancara yang telah disusun secara sistematis dan lengkap untuk pengumpulan datanya. Selanjutnya 
teknik analisis data menggunakan Miles dan Hubberman.

\section{HASIL DAN PEMBAHASAN Penerapan Model Demonstrasi dalam Pembelajaran}

Rincian kegiatan yang sudah dilakukan adalah sebagai berikut. Dalam melaksanakan pembelajaran pada pertemuan ini yaitu "Tari dengan tematik pada kelas IV" di SDN Tlogomas II di kota Malang. Pembelajaran seni tari di sekolah dasar setidaknya perlu memperhatikan aspekaspek yang bersifat fungsional, yaitu: 1) Siswa perlu menyadari fungsi-fungsi mekanisasi tubuh (sadar akan ruang diri) artinya sadar akan tubuhnya yang memiliki ukuran tinggi, lebar, dan berat. Kesadaran ini mengarahkan pada pemahaman teknis tentang bagaimana dan dengan cara apa tubuh itu digerakan. Tujuannya siswa tidak merasa asing terhadap anggota tubuhnya, seperti kaki, tangan, kepala, dan sistem persendiannya. Geridine Dimonstein (Ronoatmodjo, 1982:40).

Lebih lanjut pembelajaran terkait materi "Tematik kelas IV dengan submateri pesona kekayaan di Negeriku". Model yang digunakan

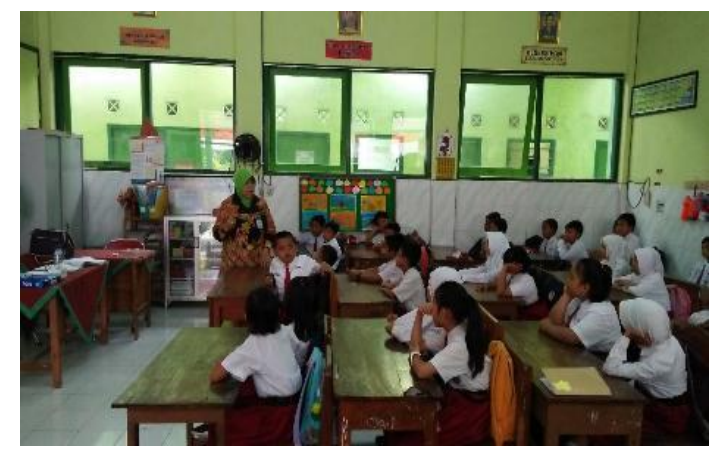

Gambar 1. Siswa menyimak cerita dari Guru dalam pembelajaran kali ini yaitu model pembelajaran demonstrasi kolaborasi direct instruction. adapun rincian kegiatan pembelajaran yang dilakukan sebagai berikut:

Siswa menyimak cerita tentang tentang permainan tradisional lainnya yaitu Fahombo Batu atau lompat batu dari kepulauan Nias, yang dilisankan oleh guru. Siswa diminta untuk menyimak dengan teliti, kemudian menemukan gagasan pokok dan gagasan pendukung dari setiap paragraf tersebut. Untuk paragraf pertama, siswa mendiskusikan jawaban bersama teman di sebelah. Paragraf ke dua dan ketiga dikerjakan secara individu dan langsung disampaikan kepada guru.

Siswa diingatkan kembali pada pembelajaran sebelumnya tentang sifat bunyi menyerap dan memantul.Guru mengajukan pertanyaan sebagai kegiatan pembuka. Siswa dibagi dalam kelompok. Dalam pembagian kelompok, guru memperhatikan keberagaman yang ada, misalkan cara berpendapat, sifat dan lain-lain. Guru akan mengamati bagaimana siswa bekerjasama dengan teman-teman yang berbeda. Siswa diberikan masalah mengenai Ibu Mimip penjaga kantin.

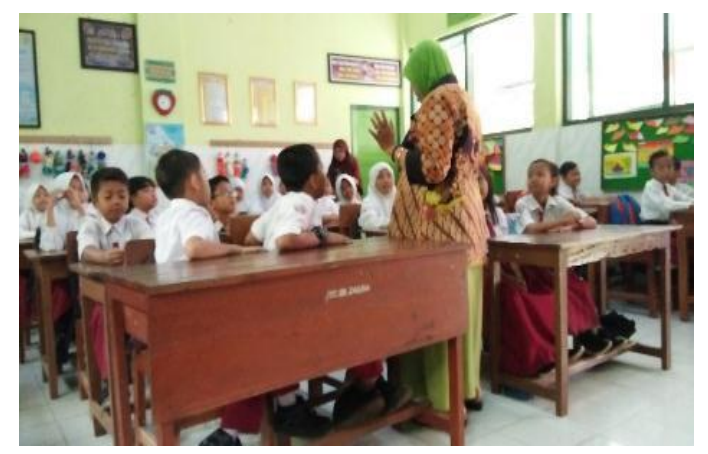

Gambar 2. Siswa dan Guru melakukan Pembagian Kelompok 


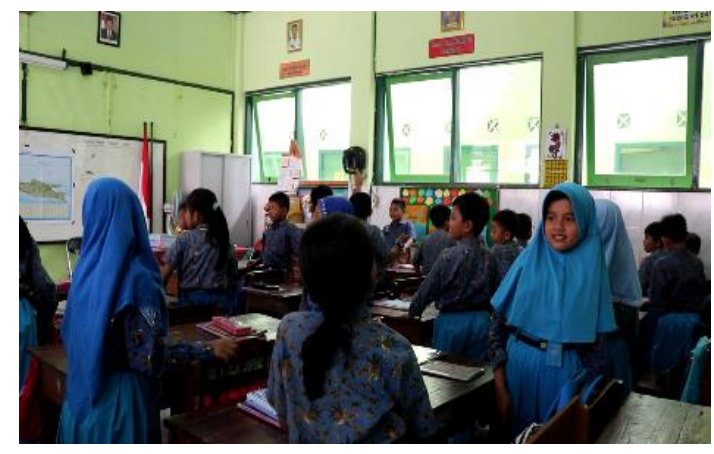

Gambar 3. Siswa membentuk kelompok untuk mencari pasangan

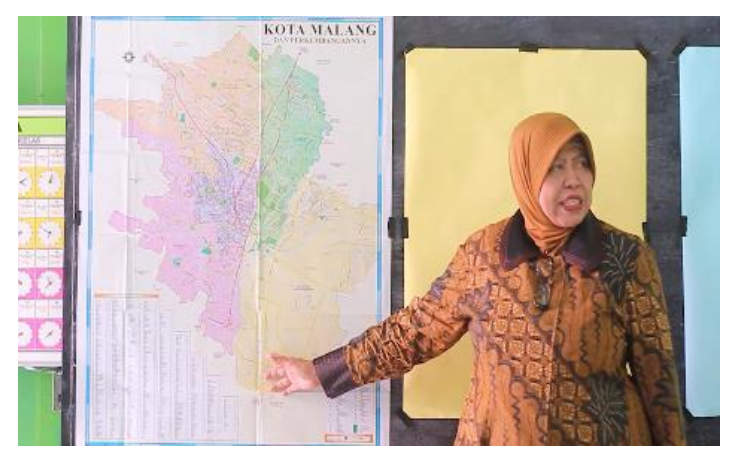

Gambar 5. Guru memperkenalkan wilayah Kota Malang menggunakan Peta

Berdasarkan kegiatan tersebut guru meminta setiap siswa untuk membentuk kelompok kemudian siswa diminta menemukan gagasan pokok dan gagasan pendukung setiap paragraf yang didengarnya. Siswa menuliskan gagasan pokok dan gagasan pendukung pada grafik yang disiapkan di buku siswa.Siswa saling menukar jawaban dengan temannya.

Pembelajaran selanjutnya guru memberikan aba-aba tepuk tangan, siswa akan mencari pasangan lagi dan menyampaikan jawabannya. Begitu seterusnya sampai siswa berganti 3 pasangan. Siswa secara individu menganalisis persamaan dan perbedaan jawabannya dengan temannya. Guru meminta siswa untuk mempresentasikan jawabannya (fokus 1 paragraf) di depan.

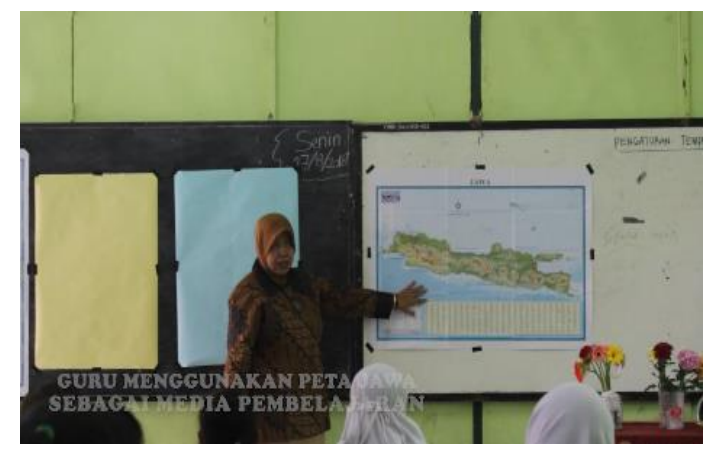

Gambar 4. Guru menggunakan media Peta

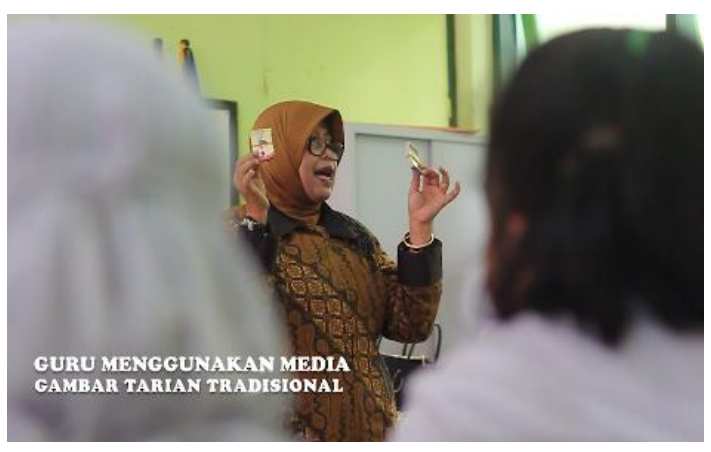

Gambar 6. Penggunaan media kartu untuk mengenal tarian tradisional

Siswa juga menyampaikan persamaan dan perbedaan jawabannya dengan temannya. Guru memberikan kesempatan kepada siswa untuk bertanya. Guru meminta kembali satu siswa untuk mempresentasikan jawabannya (paragraf 2).

Pembelajaran pada pertemuan selanjutnya dilaksanakan pada hari senin tanggal 27 Agustus 2018. Rincian kegiatan yang sudah dilakukan adalah sebagai berikut. Sebelum pembelajaran dimulai, guru mengajak siswa untuk melakukan brainstorming sebagai motivasi awal. Guru memberi motivasi belajar peserta didik secara kontekstual sesuai manfaat dan aplikasi materi ajar dalam kehidupan sehari-hari, dengan memberi contoh dan perbandingan lokal, nasional dan internasional, serta 
disesuaikan dengan karakteristik dan jenjang peserta didik dengan kegiatan tepuk semangat. Guru mengajukan pertanyaan dengan mengaitkan kompetensi yang akan dipelajari tentang gerak dasar tari Bungong Jeumpa. Guru menjelaskan tujuan pembelajaran atau kompetensi dasar yang akan dicapai, yaitu tentang gagasan pokok dan gagasan pendukung, sudut dan gerakan tarian bungong jeumpa dengan posisi duduk, keragaman sosial budaya. Guru menyampaikan cakupan materi dan penjelasan uraian kegiatan yang akan dilakukan dalam pembelajaran.

Siswa diajak berdiskusi dengan menggali informasi dari berbagai sumber, siswa mampu menjelaskan keragaman sosial di provinsi setempat sebagai identitas bangsa Indonesia secara tertulis dan lisan. Dengan menggali informasi dari berbagai sumber, siswa mampu menyajikan keragaman sosial di provinsi setempat sebagai identitas bangsa Indonesia secara tertulis dan lisan. Untuk mempermudah penjabaran materi terkait keragaman sosial, guru menggunakan media peta Kota Malang. Pemanfaatan media peta juga berfungsi untuk mengenalkan daerah/wilayah kota malang. Guru dan siswa melakukan tanya jawab terkait media dan wilayah malang raya.

Selanjutnya guru mengajak siswa berdiskusi tentang gerakan dasar tari Bungong Jeumpa untuk mengingatkan mereka tentang keterampilan yang telah mereka pelajari sebelumnya. Siswa berdiskusi dan dapat mengajukan pertanyaan kepada guru jika ada hal yang masih belum dipahami. Siswa memilih salah satu kelompok. Siswa menulis apresiasi atas penampilan tari dari kelompok tersebut dengan menjawab pertanyaan berikut yang terdapat dalam buku siswa.

Sebelum menulis, siswa diminta melakukan wawancara kepada masyarakat sekitar (teman, guru, dan orang tua). Siswa juga diminta melengkapi hasil wawancara mereka dengan berbagai sumber bacaan, seperti buku perpustakaan, surat kabar, atau berbagai sumber dari internet. Siswa diminta menuliskan informasi yang mereka peroleh secara terperinci. Siswa diajak memperhatikan kembali tangram yang telah mereka buat. Siswa diminta mencermati bangun segiempat yang terdapat pada tangram tersebut. Siswa diminta mendiskusikan dengan teman satu kelompok. Siswa diminta mengamati gambar segiempat yang terdapat dalam buku siswa, seperti yang di bawah ini. Siswa diminta memberikan penjelasan atas jawaban yang mereka berikan. Siswa diminta menyimpulkan hubungan antarsudut pada bangun segiempat? Siswa mengomunikasikan kesimpulan mereka kepada teman yang berada di satu meja secara berpasangan.

Selanjutnya untuk mengkomodir kompetensi psikomotorik siswa, guru juga menggunakan media kartu tarian tradisional. Guru menggunakan kartu tersebut agar dapat digunakan siswa secara individu maupun kelompok. Penggunaan media tersebut juga diiringi dengan sintak model demonstrasi yaitu perencaan, pelaksanaan, dan evaluasi.

Guru bersama peserta didik melakukan refleksi terhadap proses 
kegiatan yang sudah dilaksanakan Guru bersama peserta didik memberikan umpan balik terhadap proses dan hasil pembelajaran Guru bersama peserta didik melakukan kegiatan tindak lanjut dalam bentuk pemberian tugas individual maupun kelompok Guru menyampaikan rencana pembelajaran pada pertemuan berikutnya. Guru memberikan penguatan karakter bersama peserta didik dengan menyanyikan Lagu Wajib Nasional atau Lagu Daerah. Tujuan dari refleksi yaitu untuk mengetahui tingkat keberhasilan dalam pembelajaran. Hal ini sesuai dengan pendapat Domjan dan Burkhard dalam (Wahyuningsih, 2005: 10) keberhasilan dalam proses pembelajaran dipengaruhi oleh beberapa faktor yaitu faktor intern dan faktor ekstern. Lebih lanjut sebagaimana hasil penelitian yang sudah dilakukan Rara, dkk (2015) menyatakan bahwa terdapat perbedaan yang signifikan antara hasil belajar menggunakan model pembelajaran demonstrasi dengan pembelajaran menggunakan model lain.

\section{SIMPULAN}

Berdasarkan hasil penelitian didapatkan data bahwa penerapan model demonstrasi melibatkan siswa dalam berbagai situasi pembelajaran. Adapun tema materi pembelajaran dalam hal ini yaitu tema 1 Indahnya Keberagaman Subtema 3 Bersyukur atas keberagaman. Model demonstrasi dilakukan dengan mengikuti sintak atau tahapan sebagai berikut perencanaan, pelaksanaan, dan evaluasi. Tahap perencanaan dilakukan dengan membuat RPP dan media pembelajaran, tahap pelaksanaan dilakukan dengan mengintegrasikan ke dalam kelompok, dan evaluasi dilaksanakan dengan melakukan tanya jawab sebagai bentuk refleksi selanjutnya. Kendala yang dihadapi guru yaitu kurangnya sarana dan prasaran penunjang pembelajaran seperti media realita

\section{DAFTAR RUJUKAN}

Arikunto, S. (2005). Penelitian Tindakan Kelas. Jakarta: Bumi Aksara.

Baharuddin dan N. E. (2007). Teori Belajar \& Pembelajaran. Yogyakarta : ARRUZZ MEDIA

Depdikbud. (1996). Kamus Besar Bahasa Indonesia. Jakarta: Balai Pustaka.

Wahyuningsih, T. (2005). Peningkatan Pembelajaran Seni Tari Melalui Penerapan Metode Imitatif dan Penugasan di SD $N$ Sidorejo, Selomartani, Kalasan, Sleman, Yogyakarta. Skripsi tidak diterbitkan.

Prastowo, A. (2013). Pengembangan Bahan Ajar Tematik Panduan Lengkap Aplikatif. Yogyakarta: Diva Press.

Peraturan Menteri Pendidikan dan Kebudayaan Nomor 57 Tahun 2014 Tentang Kerangka Dasar dan Struktur Kurikulum Sekolah Dasar/Madrasah Ibtidaiyah.

Rara, G. P., dkk. (2015). Penggunaan Model Demonstrasi dalam Materi Ajar Instalasi Sistem Operasi. Dinamika: Jurnal Penelitian Tindakan Kelas Pendidikan Dasar \& Menengah, 5 (3). 
50 JURNAL PENDIDIKAN EDUTAMA, Vol 7, No. 1, Januari 2020 